\title{
Fatores que influenciam o compartilhamento da informação e do conhecimento
}

Adriana Rosecler Alcará

Mestre em educação e professora do Departamento de Ciência da Informação da Universidade Estadual de Londrina

Ivone Guerreiro Di Chiara

Mestre em administração de bibliotecas pela Escola de Biblioteconomia da UFMG e professora do Departamento de Ciência da Informação da Universidade Estadual de Londrina (UEL)

Jorge Luis Rodrigues

Bibliotecário graduado pela UEL em 2007. Bolsista de iniciação científica do CNPq

Maria Inês Tomaél

Doutora em ciência da informação pela Escola de Ciência da Informação da UFMG e professora do Departamento de Ciência da Informação da Universidade Estadual de Londrina (UEL).

Valéria Cristina Heckler Piedade

Especialista em Informação, Conhecimento e Sociedade pela Universidade Estadual de Londrina (UEL). Bibliotecária do Núcleo de Informações Tecnológicas (NIT) do SENAI Centro de Tecnologia da Madeira e Mobiliário (CETMAM) em Arapongas - PR.

O compartilhamento da informação e do conhecimento é essencial para a construção de novos conhecimentos, porém esse processo pode ser influenciado por diferentes fatores. Este artigo apresenta os resultados de uma pesquisa sobre o compartilhamento da informação, do conhecimento e da experiência no ambiente de pesquisa e desenvolvimento (P\&D). Os dados coletados, por meio de entrevistas, foram analisados a partir da técnica análise de conteúdo. Entre os resultados estão os principais fatores que podem interferir no processo de compartilhamento da informação, entre os quais a motivação, as barreiras e 
a obrigatoriedade; bem como as formas e os meios mais utilizados para compartilhar informação e conhecimento.

Palavras-Chave: Compartilhamento da informação e do conhecimento; Motivação para compartilhar; Barreiras no compartilhamento; Formas e meios de compartilhamento.

\section{Factors that influence information and knowledge sharing}

The process of knowledge and information sharing is essential for the construction of new knowledge even though it may be affected by several factors. This article shows the results of a research on knowledge, information and experience sharing in the context of research \& development $(R \& D)$. The data were collected through interviews and analyzed by means of the context analysis approach. Among the main factors that may interfere in the process of information sharing are: motivation, barriers and obligations and also the most common forms and means to share information and knowledge.

Keywords: Information and knowledge sharing. Motivation for sharing. Barriers in sharing. Ways and means of sharing.

Recebido em 17.08.2008 Aceito em 12.03.2009

\section{Introdução}

O conhecimento sempre foi um fator importante nas organizações, porém só nos últimos anos tem sido destacado na literatura ( $\mathrm{CHOO}, 2003$; DAVENPORT, 2000; NONAKA; TAKEUCHI, 1997), sendo considerado um elemento para a inteligência organizacional e, reconhecidamente, uma fonte para a vantagem competitiva. No entanto, há muito ainda a entender e investigar sobre como o conhecimento é criado, compartilhado e utilizado.

De acordo com Lin (2007), o compartilhamento do conhecimento pode ser definido como uma cultura de interação social em que ocorre a troca de conhecimentos, experiências e habilidades. O autor exemplifica esse processo com duas situações, sendo que a primeira refere-se à vontade ou ao desejo da pessoa de comunicar-se ativamente com seus colegas (doar conhecimento). Nessa situação a pessoa sente prazer em compartilhar e ajudar os outros. A segunda situação diz respeito à 
consulta ativa aos colegas para aprender com eles (colecionar conhecimento).

No meio acadêmico a literatura tem demonstrado que o compartilhamento é um método de aquisição da informação muito recorrente (ERDELEZ apud TALJA, 2002). Muitos estudos realizados enfocam o sistema de informação disponível para ajudar professores e pesquisadores na busca de informação, mas não abordam o intercâmbio de informações entre eles, que pode ser tanto de referências sobre documentos relevantes como de informações sobre novos métodos de estudo, e também o compartilhamento da informação e do conhecimento em áreas correlatas.

Neste artigo apresentamos os resultados parciais do projeto "Redes Sociais e Inteligência Local: Espaços da Informação". Esses resultados referem-se especificamente a um dos objetivos do projeto, que diz respeito à verificação da ocorrência do compartilhamento da informação, do conhecimento e da experiência a partir das ligações dos atores. Assim, abordamos os fatores que podem influenciar no processo de compartilhamento da informação no ambiente de pesquisa e desenvolvimento ( $P \& D)$.

\section{Fatores que interferem no compartilhamento da informação e do conhecimento}

A habilidade de identificar o conhecimento presente em uma organização depende das pessoas dessa organização, que são as que criam, compartilham e usam o conhecimento. Ipe (2003) diz que compartilhar conhecimento é basicamente o ato de tornar o conhecimento disponível para outros. Entre indivíduos, o compartilhamento é um processo que permite a uma pessoa transformar o conhecimento para que possa ser entendido, absorvido e utilizado por outros atores. Para Ipe, o uso do termo "compartilhamento" implica o processo de disponibilizar o conhecimento de tal forma que ele possa ser utilizado. Para que isso ocorra, requer-se uma ação deliberada da parte do indivíduo que possui o conhecimento. Compartilhar não implica ceder a posse do conhecimento, e sim usufruir dele juntamente com os pares.

As intenções e ações para o compartilhamento podem sofrer influências de diferentes fatores. Baseando-se em estudos teóricos e relatos de pesquisa, Ipe (2003) identificou os principais fatores que influenciam o compartilhamento do conhecimento entre indivíduos: natureza do conhecimento, motivação para compartilhar, oportunidades para compartilhar, e cultura do ambiente de trabalho.

A natureza do conhecimento é classificada pela autora em dois sentidos. O primeiro está centrado na natureza tácita ou explícita do conhecimento, fundamentalmente nos aspectos cunhados por Polany (1983) e reforçados por Nonaka e Takeuchi (1997), Davenport (2000), Choo (2003) e muitos outros autores; enquanto o segundo está na valorização do conhecimento. O valor do conhecimento é mencionado por 
Ipe, principalmente no aspecto comercial, ou seja, o conhecimento como uma propriedade de valor monetário.

No fator motivação para compartilhar, o conhecimento está inserido, entranhado nas pessoas e não flui facilmente por uma organização. De acordo com Stenmark (2001), as pessoas comumente não compartilham conhecimentos sem uma forte motivação pessoal e provavelmente não o partilhariam sem saber o que podem ganhar ou perder com isso. Essa situação, para Stenmark, pode ser evitada se o conhecimento for identificado e for disseminado dentro da organização como uma atividade sistemática.

Fatores motivacionais que influenciam o compartilhamento de conhecimento entre indivíduos podem ser divididos, de acordo com Ipe (2003), em internos e externos. Fatores internos incluem o sentimento de poder, ligado ao conhecimento e à reciprocidade que resultam do compartilhamento. Fatores externos incluem o relacionamento com 0 outro (receptor) e com a recompensa por compartilhar.

Dos fatores motivacionais internos, o sentimento de poder está vinculado à idéia de que "conhecimento é poder", e o poder pode dificultar o compartilhamento. Segundo Ipe (2003), se o indivíduo tem ciência de que o conhecimento Ihe confere importância, a tendência é acumular conhecimento. Por outro lado, a reciprocidade facilita o compartilhamento, que pode ocorrer quando os indivíduos vêem que o valor que agregam depende do quanto eles compartilham seus conhecimentos com os outros. O aspecto negativo da reciprocidade é o medo da exploração, que ocorre quando se percebe que compartilham conhecimentos, mas não vêem nenhum retorno.

Complementando essa idéia, Cohen (1998) ressalta que, implicitamente ao ato de compartilhar informações, encontra-se o sentimento de reciprocidade, ou seja, os indivíduos só compartilham se recebem algo em troca. Também inerente ao compartilhamento de informações encontra-se o fator que leva alguém a se sentir parte integrante de uma comunidade; para que um indivíduo faça parte de uma comunidade, ele deve compartilhar com os demais membros.

Em relação à reciprocidade existente no compartilhamento, Dyer e Nobeoka (2000) dizem que esta pode apresentar-se de duas maneiras: a) direta - que ocorre quando dois indivíduos exercem ao mesmo tempo os papéis de emissores e receptores de informações; e b) indireta - que acontece quando um terceiro indivíduo contribui sem a expectativa de receber algo em troca. Em relação ao terceiro indivíduo, os autores destacam que, enquanto ele não tiver a certeza de que receberá uma compensação direta em troca da informação compartilhada, ele tenderá a zelar pelas informações que detém para um posterior compartilhamento.

No que se refere aos fatores externos que influenciam a motivação para compartilhar conhecimento, Ipe (2003) menciona o relacionamento entre 0 fornecedor (transmissor) e o receptor do conhecimento. 0 relacionamento com o receptor inclui os seguintes elementos: a confiança, o poder e o status do receptor. A decisão de partilhar o conhecimento - 
no sentido de dar em troca de algo recebido - é baseada na confiança. Na ausência da confiança as práticas formais para o compartilhamento de conhecimento tornam-se insuficientes para encorajar indivíduos a compartilharem seu conhecimento dentro do ambiente de trabalho. No que diz respeito ao status, Nowak e Sigmund (2000) salientam que o ser humano tem obsessão pela reputação, pelo status que tenha adquirido ou que poderá vir a alcançar em uma comunidade ou em um círculo social no qual está inserido. O status pode ser um fator implícito para o compartilhamento de informações, porquanto este poderá ser visto com bons olhos pelos demais membros da comunidade.

Quanto a isso, Judge, Fryxell e Dooley (2000) dizem que a reputação que o indivíduo pode vir a alcançar é um dos mais importantes fatores que motivam o compartilhamento de informações, o qual pode ser intensificado no ambiente da P\&D.

As oportunidades para compartilhar integram também os fatores identificados por Ipe (2003), os quais exercem influência no compartilhamento. As oportunidades podem ser de natureza formal e informal. Para facilitar o compartilhamento do conhecimento, as oportunidades formais incluem: programas de treinamento; estruturação de grupos de trabalho; e sistema baseado em tecnologia. Bartol e Srivastava (2002) denominam tais oportunidades de interações formais e Rulke e Zaheer (2000) de Canais de Aprendizado Intencional (purposive learning channels).

Os canais de aprendizado intencional incluem sessões de treinamento formal e outros mecanismos, como boletins internos e benchmarking competitivo, pelos quais o conhecimento explícito é compartilhado. Os canais de relacionamento (Relational Channels), ao contrário, incluem com maior ênfase os mecanismos de compartilhamento informal, como contatos sociais com os pares. Os autores associam intensamente os canais intencionais à eficiência. Um outro fator interessante é que o conhecimento operacional, de contextos específicos, é mais bem disseminado por meio de mecanismos formais, como os treinamentos ou as atividades de benchmarking (RULKE; ZAHEER, 2000).

Essas iniciativas, segundo Ipe (2003), propiciam uma estrutura ambiental que favorece o compartilhamento. Os canais de aprendizado intencional são capazes de conectar um grande número de indivíduos, considerando-se a velocidade da disseminação do compartilhamento do conhecimento, especialmente por meio de redes eletrônicas e outros sistemas baseados em tecnologia.

Sem desmerecer o papel das oportunidades formais no compartilhamento, as pesquisas (BROWN; DUGUID, 1991; DOUGHERTY, 1992) indicam que a maior quantidade de conhecimento é compartilhada informalmente, por meio de canais de relacionamento e aprendizagem. Canais de relacionamento (relational channels) facilitam a comunicação face a face, a qual permite a construção da confiança, tão importante para o compartilhamento. As oportunidades informais para a interação com 
outras pessoas ajudam indivíduos a desenvolverem respeito e amizade, atitudes que influenciam seu comportamento.

Para Dougherty (1992), Brown e Duguid (1991), é por meio do compartilhamento face a face que muitas ações são desencadeadas e podem resultar em um processo de comunicação em que indivíduos se aproximam e criam hábitos comuns, como a linguagem verbal e a nãoverbal.

O processo de comunicação é inerente às atividades científicas, e o contato entre os profissionais torna-se indispensável para desencadear o fluxo da informação e do conhecimento.

Por fim, Ipe (2003) indica a cultura do ambiente de trabalho como outro fator preponderante no compartilhamento do conhecimento, visto que muitos fatores que possibilitam o compartilhamento do conhecimento são influenciados pela cultura que predomina nas subunidades e/ou, de forma geral, na organização. A cultura organizacional é reconhecidamente uma das maiores barreiras para a construção, o compartilhamento e o uso efetivo do conhecimento.

Os quatro fatores identificados por Ipe (2003) são significativos, porém, se empregados isoladamente, não exercem grande influência no compartilhamento do conhecimento. A natureza do conhecimento, a motivação para compartilhar, as oportunidades para compartilhar e a cultura do ambiente de trabalho, segundo a autora, estão interconectados; cada fator exerce e recebe influência do outro de forma não-linear. A FIG. 1 representa um modelo de compartilhamento de conhecimento entre indivíduos, modelo que apresenta os quatro fatores e ilustra o relacionamento entre eles.

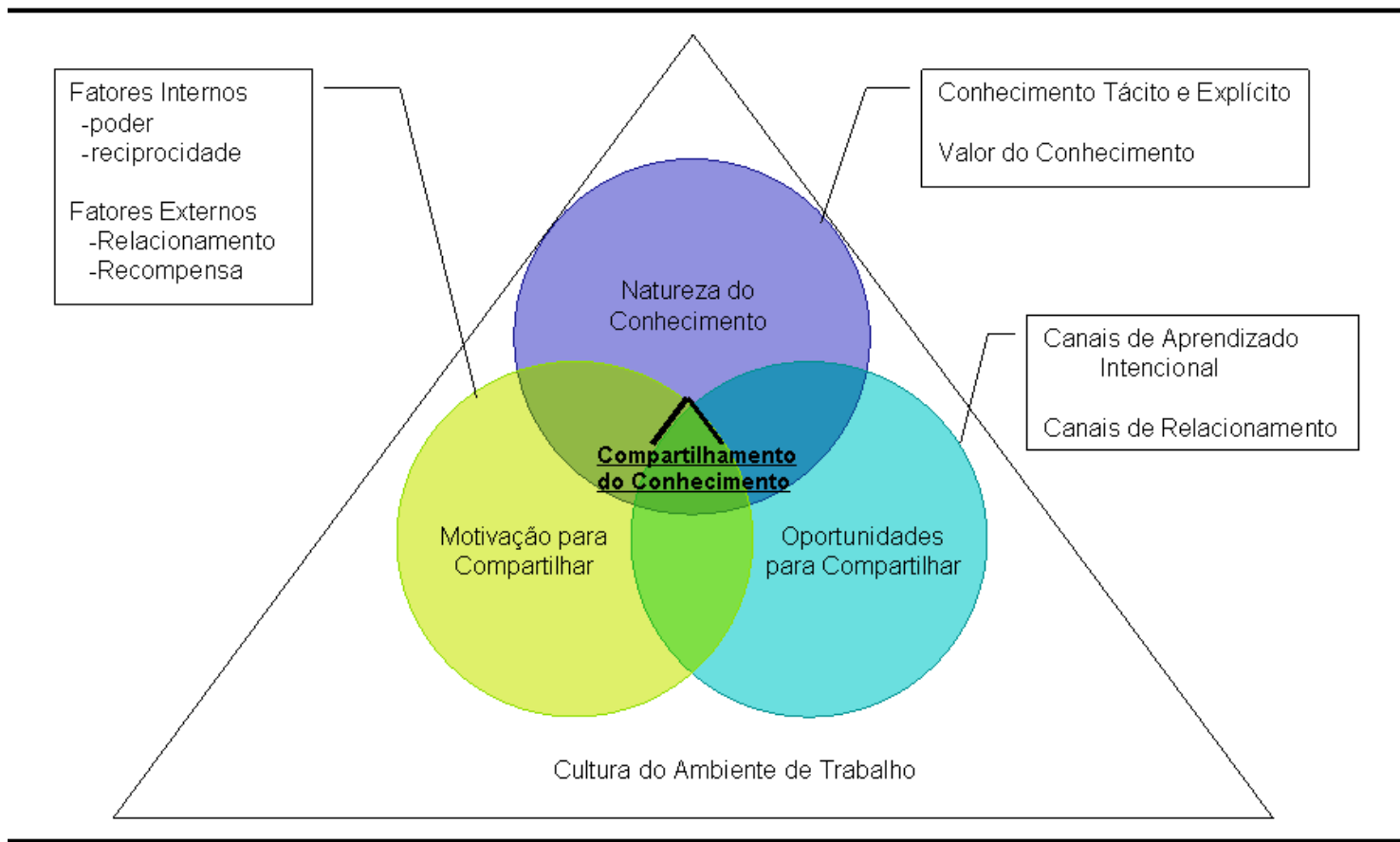

FIGURA 1 - Fatores que influenciam o compartilhamento entre indivíduos Fonte: IPE (2003). 
O modelo indica que os três primeiros fatores - natureza do conhecimento, motivação para compartilhar e oportunidades para compartilhar - estão inseridos na cultura do ambiente de trabalho, isto é, são parte integrante dela. A cultura influencia os três fatores, comandados por ela, os quais concorrem para a correta valoração do conhecimento. Desse modo, os tipos de relacionamento e de recompensa podem ser encorajados, e as oportunidades formais e informais que o indivíduo tem para compartilhar o conhecimento também podem ser mais bem aproveitadas.

A ausência de um desses fatores não impede o compartilhamento. Entretanto, no modelo de compartilhamento do conhecimento proposto por Ipe (2003), os quatro fatores estão fortemente inter-relacionados e cada um deles contribui para o compartilhamento, criando, juntos, o ambiente ideal entre indivíduos dentro de organizações para o compartilhamento do conhecimento.

O compartilhamento do conhecimento é um processo complexo, valorizado e induzido a um equilíbrio do poder dentro das organizações. 0 conhecimento é dependente do relacionamento social entre indivíduos para sua criação, compartilhamento e uso (IPE, 2003).

Ainda em relação aos motivos que podem aumentar o compartilhamento de informações, Davenport e Hall (2002) destacam que alguns indivíduos sentem prazer em relatar os resultados alcançados por determinados atos, sendo este comportamento considerado altruístico e prosaico. Em outras palavras, o compartilhamento da informação, neste caso, pode ser motivado pela satisfação pessoal de divulgar suas próprias idéias e conhecimentos.

Dyer e Nobeoka (2000) dizem que, para que ocorra o compartilhamento de informações em determinados ambientes, além das motivações existentes, a interação social é primordial. Assim, para que esta integração ocorra, são necessárias algumas ações ou técnicas, que, quando maximizadas, podem elevar o grau de compartilhamento, entre as quais figuram:

- Clareza dos objetivos da organização ou da comunidade em que o indivíduo está inserido;

- Uso de linguagens comuns para a classificação dos tipos e funções que determinadas informações podem assumir em relação aos outros;

- Participação em eventos sociais. Ou seja, com o aumento da sociabilidade um indivíduo tende a maximizar a sua rede de contatos, fato que o colocará em uma posição privilegiada em relação à quantidade e à qualidade das relações que poderão vir a ser desencadeadas, sejam elas formais ou informais;

- Disposição estrategicamente geográfica do indivíduo. Esta circunstância pode vir a aumentar o compartilhamento de informações em uma rede, mas vale ressaltar que, atualmente, com o uso intensivo dos meios de comunicação e 
das redes de informação eletrônicas, este fator tende a ser minimizado.

Outra contribuição a respeito das influências sobre 0 compartilhamento é a de Ardichvili et al. (2006), que, fundamentados na literatura, estudaram os fatores culturais que influenciam as estratégias para o compartilhamento do conhecimento em comunidades de prática virtuais e listaram potenciais diferenças culturais nos padrões de compartilhamento de conhecimento. Distinguimos as que julgamos mais importantes para o campo de ação deste estudo:

- Diferença entre gerações - pessoas mais velhas podem ser mais sensíveis às mudanças de atitudes ou posições; pessoas mais novas, especialmente as que estão expostas à influência global, podem ter um nível mais alto de tolerância para situações inesperadas ou ameaçadoras;

- Em culturas mais hierárquicas ou verticalizadas, é mister que gerentes, que estão no topo da hierarquia, controlem o fluxo da informação e delimitem as permissões para o acesso a informações críticas, situação que leva à criação de barreiras ao compartilhamento do conhecimento. A partir da participação ativa em grupos de discussão, as pessoas sentem-se à vontade para compartilhar informações sem antes consultar seus supervisores, comportamento que pode ser seriamente limitado em uma sociedade hierárquica. Para que não ocorra esse erro, isto é, para não divulgar informações sigilosas em grupos/listas de discussão, gerentes delegam essa atividade - participação em grupos - para suas secretárias ou colaboradores;

- Uma outra barreira à participação em comunidades on-line pode ser a preferência cultural para a comunicação face a face; isso pode depender da concepção cultural e da forma de comunicação que conduz e estabelece a confiança.

Uma outra abordagem a respeito dos fatores que interferem no compartilhamento é a de O'Delle e Grayson (1998). Esses autores identificaram as barreiras existentes para o compartilhamento do conhecimento e das melhores práticas das organizações. A maior barreira, segundo eles, é a ignorância, pois nem os indivíduos que atuam como fonte de conhecimento, nem aqueles que poderiam ser receptores, sabem o que é preciso partilhar e quem tem o que partilhar. Vencer essa barreira é um desafio para a gestão do conhecimento. A segunda grande barreira é a capacidade de absorção do receptor, isso porque, mesmo superada a primeira barreira, o receptor pode não ter tempo nem recursos para implementar uma prática assimilada. E, como terceira barreira, os autores mencionam a falta de relacionamento entre a fonte e o receptor do conhecimento, ou seja, a falta de vínculos pessoais entre ambos, falta de credibilidade e de esforço suficiente para ouvir ou ajudar os outros. 
Ponjuán Dante (2004) ressalta que o compartilhamento de conhecimentos organizacionais é o processo mais importante relacionado ao conhecimento. Porém, como os demais autores citados, ela afirma que o compartilhamento é o processo que enfrenta as maiores barreiras nos planos cognitivo, afetivo e organizacional. É difícil partilhar conhecimentos relacionados a pontos de vista e conceitos ao responder a perguntas e demonstrar técnicas. Com relação ao plano organizacional, os membros de uma organização não são recompensados por ajudar os colegas na resolução de problemas. Além disso, a autora destaca como obstáculos ao compartilhamento: falta de confiança, diferenças nos marcos de referência, falta de tempo e de oportunidades, recompensas pouco significativas para os que possuem conhecimento, falta de capacidade dos receptores para absorver novos conhecimentos, entre outros.

Enfim, são diversos os fatores que podem dificultar ou motivar o compartilhamento da informação e do conhecimento. Dessa forma, as organizações, além de promoverem a cultura do compartilhamento, devem identificar os aspectos que representam barreiras para a troca de informações, bem como fomentar ações impulsionadoras dos fatores que influenciam positivamente as atitudes e os comportamentos voltados para o compartilhamento.

\section{Procedimentos metodológicos}

Os procedimentos metodológicos para a realização da pesquisa foram efetivados em duas etapas:

1. a primeira etapa teve como campo de pesquisa a Rede de Cooperação e Inovação em Alimentos Funcionais do Estado do Paraná ${ }^{1}$. Essa etapa compreendeu uma pesquisa exploratória - utilizando a metodologia de "Análise de Redes Sociais $(\text { ARS })^{\prime 2}$ - e o levantamento dos contatos entre os pesquisadores cadastrados nessa rede por meio de um questionário. Os resultados (TOMAÉL et al., 2007) revelaram que 32 atores são os que mais influenciam o fluxo de informação, sendo os indivíduos mais centrais da rede;

1 A rede "formada em 2005, tem a missão de reunir ativos para impulsionar o campo de estudo de alimentos funcionais do Estado do Paraná, por meio da articulação de agentes de inovação [...] conta com a participação de cinco universidades públicas estaduais (Universidade Estadual de Londrina - UEL, Universidade Estadual de Maringá - UEM, Universidade Estadual de Ponta Grossa - UEPG, Universidade Estadual do Oeste do Paraná - UNIOESTE e Universidade Paranaense - UNIPAR), duas universidades federais (Universidade Federal do Paraná - UFPR e Universidade Tecnológica Federal do Paraná - UTFPR), duas universidades privadas (Universidade Norte do Paraná - UNOPAR e Pontifícia Universidade Católica do Paraná PUCPR), três institutos de pesquisas (Instituto Agronômico do Paraná - IAPAR, Empresa Brasileira de Pesquisa Agropecuária - EMBRAPA Soja e Instituto de Tecnologia do Paraná TECPAR) e também com a Associação do Desenvolvimento Tecnológico de Londrina - ADETEC" (TOMAÉL et al., 2007, p.118-119).

2 "[...] metodologia que estuda como o indivíduo está integrado a uma estrutura e como essa estrutura emerge das relações entre eles. Em síntese, a ARS constitui-se do mapeamento e da identificação de medidas do fluxo da informação" (TOMAÉL et al., 2007, p.114). 
2. a segunda etapa - entrevista (gravada) - envolveu 28 dos 32 atores que se mostraram mais centrais na rede (mapeada na primeira etapa). Quatro dos atores considerados influentes (resultados da primeira etapa) não participaram dessa segunda etapa por estarem fora do país, em capacitação ou licença sabática.

A entrevista seguiu um roteiro semi-estruturado, elaborado para levantar as formas e as bases do "compartilhamento da informação, do conhecimento e da experiência entre os atores" e outros pontos que não foram abordados neste artigo. Dos 28 atores entrevistados, 21 são da UEL, três da UEM, um da UFPR, dois da PUC-Curitiba e um da EMBRAPASoja. A maioria dos entrevistados está na UEL, pelo fato de essa universidade manter o maior número de pesquisadores cadastrados na Rede de Cooperação e Inovação em Alimentos Funcionais do Estado do Paraná.

Após a coleta de informações, as entrevistas foram transcritas e analisadas tendo-se como parâmetro a técnica de análise de conteúdo temas e categorias.

A análise de conteúdo consiste em três etapas, destacadas por Bardin (1977):

1. Pré-análise - organização do material coletado;

2. Exploração do material - codificação, classificação e categorização, ou seja, um estudo aprofundado do material coletado;

3. Tratamento dos resultados, inferência e interpretação - é a fase de síntese e seleção dos resultados. Nessa etapa, a reflexão e a intuição (baseada nos materiais) possibilitam estabelecer relações e aprofundar as idéias.

No caso desta pesquisa, a pré-análise consistiu na transcrição direta dos dados gravados durante a entrevista. Na segunda fase (exploração do material) foi feita a categorização das informações coletadas, tendo-se como foco os seguintes temas: a) motivação para compartilhar; b) barreiras no compartilhamento; c) obrigatoriedade para compartilhar; d) formas e meios de compartilhamento. Por fim, foram feitas as interpretações e inferências a partir dos depoimentos dos entrevistados.

\section{Análise dos resultados}

Os fatores que interferem no compartilhamento da informação identificados neste estudo estão apresentados de acordo com os quatro temas definidos para a análise.

No decorrer da análise, incluímos parte dos depoimentos fornecidos pelos entrevistados, com o objetivo de ilustrar e reforçar as interpretações. Optamos por representar a autoria desses depoimentos com letras, para preservar o sigilo dos dados. 


\subsection{Motivação para o compartilhamento}

Um dos fatores que influenciam o compartilhamento da informação e do conhecimento é a motivação. Podemos definir a motivação como aquilo que impulsiona a pessoa a agir de determinada forma, a ter determinada atitude ou comportamento diante de uma situação.

Analisando os resultados da pesquisa, foi-nos possível identificar alguns elementos, como, por exemplo, a confiança, a amizade, a afinidade, a harmonia e a doação, que podem interferir na motivação para o compartilhamento. A ação relacionada a esses elementos tem algumas características que são de origem interna; e é construída ao longo do tempo, uma vez que envolve valores, crenças, sentimentos e interesses em comum. Vale a pena mencionar que, quando a origem de uma ação é interna, as pessoas sentem-se mais autônomas e estabelecem as próprias metas e ações. Nesses casos, as atitudes e as intenções para o compartilhamento têm origem na própria pessoa, não dependendo de incentivos externos. Dessa forma, a confiança, a amizade, a afinidade, a harmonia e a doação podem ser consideradas elementos que promovem comportamentos motivados e influenciam positivamente 0 compartilhamento da informação e do conhecimento.

A confiança quebra barreiras, possibilita a interação entre as pessoas e, muitas vezes, pode ser um fator preponderante para que 0 compartilhamento de informações e de conhecimentos ocorra de forma eficaz e satisfatória. Podemos ilustrar isso com um dos exemplos mencionados por um dos pesquisadores entrevistados, que tem na sua rede de relacionamentos uma parceria com um pesquisador no Japão. Em algumas situações, esse pesquisador compartilhava os resultados de suas pesquisas antes de publicá-los. É possível visualizar nesse exemplo a importância da relação de confiança, que motivou o pesquisador a comunicar suas idéias com seu par.

A seguir, na transcrição de um dos trechos da entrevista, também é apontada a relevância da relação de confiança para o compartilhamento: "[...] este processo, naturalmente, depende, como eu já disse, de relacionamento e de confiança mútua, porque parceiros precisam ser parceiros na plenitude da palavra, se não nada se desenvolve, é uma questão de cumplicidade [...]" (ISS).

De acordo com Ipe (2003), a decisão de compartilhar conhecimento depende da relação de confiança. Além disso, quando não há confiança, as próprias práticas formais para o compartilhamento podem ser prejudicadas, inibindo as trocas de informação e conhecimento.

Um outro aspecto evidenciado quanto à confiança é a capacidade profissional do parceiro, isto é, a pessoa com quem o pesquisador se propõe a compartilhar informações precisa ter condições de dar respostas rápidas aos problemas decorrentes de detalhamentos de produtos, procedimentos metodológicos, etc. Se o pesquisador tiver uma dificuldade 
e o parceiro não conseguir ajudar, não "der conta", a parceria se enfraquece e pode até ser extinta, porque, nesse caso, rompem-se as relações de confiança. Aqui, especificamente, as parcerias estabelecidas implicam realmente troca, ou seja, um deve oferecer ao outro alguma coisa; e a confiança está relacionada à certeza que um tem do desempenho e da capacidade de resposta do outro.

No que diz respeito à afinidade, à harmonia e à amizade, é importante dizer que essas fortalecem o vínculo entre as pessoas. Quando os valores pessoais, as crenças e as expectativas são semelhantes, cria-se um clima harmonioso, com fortes tendências à comunhão de interesses e idéias. A importância da afinidade ficou evidente na fala de um dos entrevistados que, ao ser questionado sobre o motivo para a troca de informações, ressaltou que "[...] a afinidade também é importante, porque você não vai trabalhar com uma pessoa que você não se dá bem, só porque a temática é interessante, então a afinidade conta bastante" (LAU).

Outra situação em que a amizade pode contribuir para o compartilhamento é quando há o acesso a determinados recursos (por exemplo, para a manutenção de equipamentos), o qual pode ser facilitado por intermédio de amigos. O acesso a recursos físicos com a colaboração de amigos pode significar que, anterior à obtenção dos recursos, houve o acesso à informação, por meio do compartilhamento. Então, podemos inferir que as relações de amizade facilitam o compartilhamento da informação pela presença da confiança na relação.

O último elemento, a doação, refere-se ao ato de doar conhecimento sem receber nada em troca, comportamento que exemplifica a motivação intrínseca (disposição natural e espontânea de realizar determinada atividade). Nesse caso, a pessoa tem um sentimento de prazer em compartilhar suas idéias com os demais colegas, em auxiliar o próximo sem receber nada em troca. Este processo pode ser chamado de internalização, em que a pessoa já assimilou o valor e a importância do compartilhamento. Essa situação pode ser visualizada quando um dos entrevistados, ao ser questionado sobre a importância das trocas e parcerias, ressaltou que nesse processo se aprende muito e que, muitas vezes, colaborou com os pares, compartilhando seus conhecimentos e experiências sem nunca cobrar nenhum retorno e que ainda, quando menos esperava, outros pesquisadores contribuíram com informações para os seus estudos. Nesse caso podemos estabelecer uma relação com a idéia de Lin (2007), que, ao definir o compartilhamento, se reporta à cultura da interação social, em que o desejo ou a vontade de comunicarse é tão ativa que motiva a pessoa a doar conhecimento. Dixon (2000) também assegura que as pessoas gostam de compartilhar o que sabem. A autora afirma ainda que as pessoas se sentem valorizadas quando dividem as suas experiências com as outras. Isso nos permite inferir que a valorização pode contribuir para a superação de barreiras ao processo de compartilhamento. 


\subsection{Barreiras no compartilhamento}

Embora o ser humano tenha uma tendência natural para compartilhar o que sabe, existem fatores que contribuem para retardar e até impedir o processo de compartilhamento da informação. Esses fatores podem ser de ordem estrutural, logística, cultural e psicológica, inerentes aos indivíduos e à própria organização na qual eles atuam.

Nas entrevistas realizadas com os pesquisadores, percebemos que um grande obstáculo ao compartilhamento é a falta de confiança no outro, o que nem sempre é um sentimento sem causa, pois alguns deles relataram episódios em que foram "vítimas" da apropriação de idéias e produtos por parte dos parceiros.

Reportando-se a uma parceria com um órgão de pesquisa, um pesquisador relata que o seu grupo de pesquisa desenvolveu sozinho um projeto de reator e, por ocasião da instalação do reator, o órgão que financiou a pesquisa decidiu pela sua implantação em outro local e não na cidade dos pesquisadores. Segundo o pesquisador, esse órgão ganhou "pronto" o reator.

O medo da exploração nas relações de parceria é uma barreira para o compartilhamento do conhecimento, e é citado por Empson (2001) como um aspecto negativo da reciprocidade, negociada ou não, em tais relações.

É fato que as parcerias para pesquisas que envolvem ou não financiamento possibilitam 0 acesso às informações provenientes da pesquisa a todos os parceiros, inclusive as informações sigilosas, o que, dependendo da parceria, pode resultar na apropriação da idéia e dos próprios resultados do projeto.

O pesquisador universitário tem uma cultura voltada para a disseminação dos resultados da pesquisa e até do projeto, mas é preciso proteger a informação, o que não significa necessariamente não compartilhar. É preciso estimular o compartilhamento das informações, mas de modo a assegurar também a sua propriedade.

Ainda com relação à confiança e ao sigilo, um dos entrevistados mencionou a necessidade de assinatura do que ele chamou de carta de sigilo, porque, segundo ele "[...] não tem crescimento se nós não dividirmos a informação [...]" (ISS). Mas esse mesmo pesquisador relatou que, quando se reúnem para a assinatura da mencionada carta, ninguém fala a verdade. Ainda, ele mencionou um outro problema além dos parceiros quando se trabalha com inovação tecnológica: os alunos, na universidade, são presença obrigatória nos projetos de pesquisa e eles nem sempre têm maturidade suficiente para evitar o vazamento de informações. Para esse entrevistado, as empresas não investem na universidade porque conhecem a vulnerabilidade das informações geradas; afinal, o professor/pesquisador é obrigado a publicar e nem sempre consegue fazer isso protegendo as informações. 
A desconfiança e o medo do plágio e do roubo das idéias e dos resultados estão presentes na comunidade científica, e são fatores que retardam e impedem a discussão de idéias e o compartilhamento das informações, tão importantes para o avanço da ciência e da tecnologia. Isso nos remete ao antigo dilema: compartilhar ou proteger?

Ainda com relação aos desafios relacionados ao compartilhamento da informação, outro pesquisador admitiu não se tratar de um processo fácil, porque existe muita competição entre os pesquisadores e interesses pessoais que interferem nessa troca.

Infelizmente, em muitas situações ainda prevalece o sentimento do reconhecimento individual em detrimento do coletivo, o que é um equívoco, pois, se um determinado grupo se torna referência nacional e até internacional sobre determinado assunto, a área se fortalece e todo mundo ganha.

É preciso lembrar ainda que nessas situações as pessoas podem, além do reconhecimento individual, perceber o valor da informação que possuem. Essa percepção passa a ser uma barreira porque, como afirmam Andrews e Delahaye (2000), as pessoas podem clamar pela propriedade emocional do conhecimento e esse senso de propriedade está relacionado, em muitos casos, ao status e às possibilidades de avanço na carreira.

Essa idéia contraria a argumentação de Judge, Fryxell e Dooley (2000), para os quais o compartilhamento oferece visibilidade para quem o faz e isso pode angariar prestígio e reputação.

A interação social, que é um fator facilitador do compartilhamento da informação, nem sempre ocorre nas universidades, pois os laboratórios isolam os pesquisadores e contribuem para inviabilizar a troca, a conversa e o contato.

Esse isolamento contraria o que recomendam O' Dell e Grayson (1998) para facilitar o compartilhamento de conhecimento, quando dizem que as organizações devem assegurar condições logísticas, estruturais e culturais que estimulem a troca de informações entre seus membros.

Se a desconfiança é um dos maiores obstáculos para o compartilhamento, a interação social possibilita o desenvolvimento de vínculos entre os indivíduos e, conseqüentemente, gera confiança; por isso deveria ser estimulada quando se considera o compartilhamento necessário ao avanço da pesquisa.

Outro obstáculo ao compartilhamento da informação mencionado pelos pesquisadores entrevistados pode ser considerado de ordem estrutural, pois não existe uma escala de trabalho intermediária entre a de laboratório e a industrial, o que dificulta o estabelecimento de parcerias com o empresariado.

Um pesquisador da área de biologia complementa que a universidade não dispõe de mecanismos para atender à demanda da sociedade. É fato que essas instituições não dispõem de mecanismos para que as atividades desenvolvidas no âmbito acadêmico tenham um reflexo social rápido e efetivo. Por outro lado, há que se considerar a falta de comprometimento dos gestores das universidades com relação às 
demandas da sociedade, como também o desenvolvimento da pesquisa que acontece dentro do academicismo, totalmente desvinculado de ações empreendedoras. O que ocorre nesse caso é que, mesmo quando partilham com os empresários os resultados de suas pesquisas, os pesquisadores não encontram eco, ou seja, apoio, porque há um descompasso entre a academia e o meio produtivo.

A literatura (PONJUAN DANTE, 2004; SELAMAT; CHOUDRIE, 2004) é unânime em apontar dificuldades no compartilhamento do conhecimento. Essas dificuldades nos parecem mais evidentes no caso do conhecimento tácito, muito rico em organizações empresariais. No contexto estudado, essas barreiras poderiam ser atenuadas, uma vez que a maior parte do conhecimento produzido é explicito, com vistas à sua disseminação, o que é parte da cultura acadêmica, estimulada pela obrigatoriedade da comunicação dos resultados de pesquisa.

\subsection{Obrigatoriedade para compartilhar}

Um dos elementos que impulsionam o compartilhamento da informação e do conhecimento é a obrigatoriedade, que está relacionada à necessidade de laboratório, de infra-estrutura, de resolução de problemas ou de conhecimentos de especialistas.

Atualmente, o ambiente de pesquisa de alguns departamentos da universidade é deficitário em laboratórios, equipamentos e tecnologias necessárias para o processo de determinadas pesquisas, principalmente quando se trata de estudos que demandam testes e experimentos. Assim, a solução encontrada pelos pesquisadores é a utilização da infra-estrutura dos demais departamentos da universidade e de outras instituições. $E$, nessa interação, podem surgir necessidades e oportunidades para o compartilhamento da informação. A busca por laboratórios mais bem equipados pode iniciar uma parceria que leva ao compartilhamento. Inicialmente, pode ser uma parceria formal, uma troca formal, mas depois pode transformar-se em relações informais.

No que diz respeito ao conhecimento de especialistas, vale mencionar que, em determinados estudos, há a necessidade do conhecimento de um especialista de outra área para complementar a pesquisa ou resolver algum problema. Nessas situações, o pesquisador que solicita a ajuda pode compartilhar as suas informações com 0 especialista e este compartilhar as informações que poderão solucionar os problemas identificados.

É importante frisar que para o desenvolvimento de todo o processo de pesquisa algumas etapas dependem de outras áreas, para isso o compartilhamento de informações (sobre a pesquisa e seus delineamentos) é imprescindível. Esse tipo de compartilhamento possibilita a complementação e a aproximação de conhecimentos de áreas distintas.

Tratando-se da resolução de um problema no processo da pesquisa, podemos ressaltar a motivação pela busca de informação por meio de 
canais formais, tais como livros, periódicos, etc., e de canais informais, como, por exemplo, um contato pessoal com um colega de departamento ou com outros pesquisadores que trabalham com o mesmo tema. As oportunidades para o compartilhamento podem ocorrer quando 0 pesquisador expõe ou relata ao seu colega o andamento daquela atividade ou processo, com o objetivo de evidenciar o problema ocorrido. Nessas ocasiões, ambos os pesquisadores podem trocar conhecimento e experiência, com um objetivo comum: resolução dos problemas de pesquisa. No depoimento a seguir podemos visualizar um exemplo de busca de informação para solução de problemas de pesquisa:

[...] a gente busca informação na literatura, em contatos com outras pessoas ou centros e em trocas de e-mails [...] você sabe de uma pessoa que trabalha em outra instituição e que desenvolve alguma coisa parecida, então a gente troca informação, [...] eu já busquei solução de problemas com o pessoal da EMBRAPA, o pessoal da UNICAMP e mesmo os professores daqui a gente busca essa interação, para solução dos problemas (REN).

Outro entrevistado, quando questionado sobre como resolve os problemas que surgem no decorrer da pesquisa, relatou que a solução vem a partir de muita conversa, interação e troca de experiências com colegas de pesquisa. Destacou, ainda, a importância de se buscar a experiência (metodologias, técnicas de investigação e outras) de grupos de pesquisa que são referência na sua área de atuação.

O cotidiano da pesquisa requer o compartilhamento freqüente, pois, muitas vezes, o pesquisador não dispõe de tempo suficiente para buscar na literatura respostas para as suas dúvidas, ou então busca e não as encontra. Além disso, às vezes é necessário discutir muito para se chegar a uma reposta que seja considerada de consenso para o grupo de pesquisadores.

Outros aspectos que podem ser considerados elementos da obrigatoriedade para o compartilhamento são o reconhecimento e a avaliação do trabalho do pesquisador pelos seus pares. Isso acontece quando o pesquisador apresenta sua pesquisa em algum evento ou a publica em algum veículo informacional (livro, periódico, etc.). A comunicação científica, por meio de canais formais, é uma forma de compartilhamento que permite, desse modo, a avaliação do seu trabalho e, conseqüentemente, a retomada do que eventualmente pode não estar dando certo. É uma oportunidade para o crescimento.

Enfim, podemos afirmar que os aspectos que integram a obrigatoriedade - busca de equipamentos, laboratórios, resoluções de problemas e conhecimentos de pesquisadores ou especialistas da mesma área - podem converter-se em oportunidades para o compartilhamento de informações. E esse processo, inicialmente de natureza formal, pode fortalecer os canais de comunicação informais, ou seja, as relações 
informais, em que a troca e o compartilhamento de informações e de conhecimento podem ocorrer de forma mais natura.

\subsection{Formas e meios de compartilhamento}

Ipe (2003) considera que o compartilhamento do conhecimento individual é imperativo para a criação, a disseminação e a gestão do conhecimento em todos os níveis da organização. Corroboram essa argumentação Nonaka e Takeuchi (1997), para os quais não é possível criar conhecimento sem as pessoas e, principalmente, se não houver compartilhamento do conhecimento individual.

Para que ocorra o compartilhamento do conhecimento, seja ele individual ou corporativo, assegurando assim a realização desse processo, é preciso a escolha de um meio eficaz. Esses meios podem ser diretos ou indiretos. Nos meios diretos, as relações para a obtenção de informação podem acontecer com as pessoas que os próprios pesquisadores conhecem, com os colegas na universidade, com antigos colegas de mestrado e doutorado, com professores, etc. No que diz respeito aos meios indiretos, a busca da informação se dá por meio da literatura; as leituras podem suscitar questões, que fazem os pesquisadores buscarem o compartilhamento com o autor, que é, então, procurado tanto por seus pares quanto pelas pessoas que leram seus artigos ou se interessam por eles.

Esse segundo tipo de compartilhamento configura-se no compartilhamento unilateral, ou seja, quando se trata da relação entre um leitor e um texto de seu interesse. O autor compartilha seu conhecimento quando escreve e o pesquisador/leitor absorve a informação e o conhecimento disseminado pelo texto. Ocorre nesse caso um diálogo entre o compartilhador/autor e o receptor da informação. O sucesso desse diálogo como meio para o compartilhamento da informação depende do compartilhador (principalmente da sua capacidade de comunicação), mas depende também das condições cognitivas do receptor.

Nesta pesquisa constatamos que os entrevistados se utilizam tanto dos meios diretos quanto dos indiretos como canais para 0 compartilhamento. As falas transcritas a seguir, de dois dos entrevistados, exemplificam o uso do canal indireto:

Com certeza na hora em que você tem uma idéia ou alguma coisa que te chama atenção, de alguma forma eu poderia montar um projeto disso, isso daí já leva você a ter que se informar, então você vai ter que fazer muita leitura, dos artigos, mesmo de livros para se interar mais naquela idéia, mas ao longo da pesquisa, você está continuamente necessitando desse conhecimento (REN). [...] normalmente é com a literatura científica, com os próprios resultados que a gente obtém no laboratório, que a gente vai dando continuidade, e sempre comparando com outros 
pesquisadores internacionais para ver o que está acontecendo. [...] sempre a literatura científica e os pares (LIA).

A informação obtida por meio de leituras é comum no ambiente de pesquisa, tanto para a atualização, busca de novas idéias, respaldo científico, quanto para a solução de problemas. O pesquisador é um leitor dos materiais de sua especialidade, se tornando receptor de conhecimentos, e o autor, no processo da leitura, é o especialista.

Já com relação aos meios diretos para a realização do compartilhamento, verificamos serem muito comuns entre os entrevistados. Como exemplo, podemos citar os e-mails, os contatos face a face, as listas de discussão e até mesmo o telefone.

No que se refere à interação face a face, esta é considerada pela literatura (DAVENPORT; PRUSAK, 1998; DIXON, 2000) como o meio mais eficaz para o compartilhamento da informação. A proximidade física e a informalidade existentes no contato face a face são fatores que influenciam positivamente a troca de informações. A informalidade desse modo de contato não impõe tanta censura quanto outros, como, por exemplo, a apresentação de trabalhos em eventos. Os entrevistados desta pesquisa, em sua maioria, citaram a interação face a face como o principal meio para a realização do compartilhamento, o que é compreensível considerando-se as vantagens dessa opção de compartilhamento em relação às demais. Ipe (2003) considera a confiança como fator de motivação para o compartilhamento; e confiança é algo que exige proximidade, conhecimento do outro e existência de vínculos.

Os eventos presenciais também contribuem para a preferência do compartilhamento face a face, sendo este tipo de contato considerado mais eficiente quando comparado com outros meios de comunicação.

O avanço das Tecnologias de Informação e Comunicação (TIC's) tende a aprimorar e promover o compartilhamento de informações e conhecimentos, já que este pode ocorrer através de diversos canais comunicacionais, mas ainda assim observarmos a prevalência do contato face a face.

No que concerne ao papel das TIC's, em ser mais uma ferramenta de auxílio à promoção do compartilhamento de informações e conhecimentos, destacam-se as comunidades virtuais. Mas vale ressaltar a incipiência destas no Brasil, fato este que se pode observar pelo conteúdo das mensagens que veiculam nestas listas de discussão, majoritariamente comunicados, sendo que quase não se observa a discussão sobre um tema. Em outros países esse é um meio em que o compartilhamento de fato acontece.

Analisando os dados da pesquisa, podemos destacar também, como um grande canal de compartilhamento, o uso de e-mail; porém estas mensagens geralmente são curtas, objetivas e diretas, talvez por economia de tempo na comunicação. Em alguns casos, a comunicação por e-mail pode conter a troca de arquivos de todos os tipos - artigos, relatórios, trabalhos de alunos, etc. 
Diante do exposto, podemos dizer que a interação face a face propicia o desenvolvimento de vínculos que promovem a relação de confiança e permitem a continuidade do processo de compartilhamento.

\section{Considerações finais}

O conhecimento necessário para o desenvolvimento de uma pesquisa é construído durante o seu curso, e esse é um processo subsidiado por informação, desde o início até a conclusão. Essa informação vem, primeiramente, da literatura, e em seguida da experiência e do conhecimento detido pelos pesquisadores e especialistas, além da relação com alunos e orientandos. Observamos, neste estudo, que o compartilhamento entre pesquisadores permeia todo o processo de pesquisa e lhe é imprescindível, visto que os efeitos do compartilhamento da informação constituem-se elementos relevantes e, em muitos dos casos, de fácil acesso.

As dificuldades encontradas no processo de pesquisa, como infraestrutura, conhecimento complementar de especialistas ou busca por soluções para problemas encontrados, levam o pesquisador a compartilhar informações, conhecimento e sua experiência. Essas dificuldades possibilitam a criação e/ou fortalecimento das relações com pares e especialistas de áreas de interface, situação que permite a construção do conhecimento de ambas as partes, tanto de quem busca a informação quanto de quem a fornece.

O conhecimento que as pessoas possuem é o que atrai outros pesquisadores. Quando cada um, com seu conhecimento e sua especialidade, se une a outros, forma-se um todo. E é esse conhecimento coletivo, de que cada pesquisador detém uma parte, que move as parcerias e promove o compartilhamento.

É importante também destacar que o compartilhamento de informações e de conhecimentos entre diferentes pesquisadores e instituições, por meio da complementaridade de conhecimentos, pode vir a gerar novas idéias de pesquisa e também a formação de parcerias benéficas ao aprimoramento da P\&D intra e extra-institucionais.

Os dados analisados ainda revelam que os atores enfrentam barreiras quanto ao compartilhamento da informação e do conhecimento, apesar do campo empírico do estudo ser constituído por instituições de ensino e pesquisa, cuja produção científica deve ser disseminada para ter seus resultados validados mediante avaliações, discussões e análises. Portanto, o compartilhamento da informação, do conhecimento e da experiência faz parte da cultura dessas instituições.

As barreiras identificadas são decorrentes da falta de confiança mútua, do medo do plágio, do roubo das idéias e da própria estrutura das instituições, que isola os pesquisadores em laboratórios. Além disso, a informação, o conhecimento e a experiência, ao mesmo tempo em que conferem reconhecimento e visibilidade a quem os detém, inspiram um 
sentimento de propriedade; sentimento que, aliado à necessidade de proteção, resulta no comprometimento do processo de compartilhamento.

A confiança também é um elemento que pode interferir na motivação para compartilhar informação. A presença da confiança promove a interação e tende a deixar as pessoas à vontade para compartilhar suas experiências e seus conhecimentos. Podemos destacar ainda outros indicadores no que se refere à motivação para o compartilhamento, como a amizade, a afinidade e a harmonia, que se constituem em importantes elementos para o fortalecimento dos vínculos entre as pessoas e propiciam um ambiente favorável ao compartilhamento.

Com relação às formas e aos meios de compartilhamento da informação e do conhecimento, constatamos que os atores entrevistados utilizam todos os recursos disponíveis abordados pela literatura - diretos e indiretos -, inclusive aqueles propiciados pela tecnologia de informação e comunicação. No entanto, os dados analisados evidenciam que o contato face a face é, também entre os entrevistados, o preferido para o compartilhamento; o que reforça a ênfase da literatura com relação a essa forma de compartilhamento, que, em decorrência da proximidade entre os atores, favorece a criação de vínculos importantes entre eles, como a amizade e a confiança, sentimentos que estimulam naturalmente 0 compartilhamento.

São muitos os fatores que podem interferir no compartilhamento da informação e do conhecimento. A análise desses fatores nos permite inferir que as intenções e ações voltadas para o compartilhamento precisam ser estimuladas e valorizadas constantemente, por meio de oportunidades formais e informais, elementos motivadores, aspectos culturais e, principalmente, pela promoção da relação de confiança.

\section{Referências}

ANDREWS, K. M.; DELAHAYE, B. L. Influences on knowledge progress in organizational learning: the psychosocial filter. Journal of Management Studies, v. 37, n. 6, p. 797-810, Sep. 2000.

ARDICHVILI, A. et al. Cultural influences on knowledge sharing through online communities of practice. Journal of Knowledge Management, v. 10, n. 1, p. 94-107, 2006.

BARDIN, L. Análise de conteúdo. Lisboa: Edições 70, 1977.

BARTOL, K. M.; SRIVASTAVA, A. Encouraging knowledge sharing: the role of organizational reward systems. Journal of Leadership \& Organizational Studies, v. 9, n. 1, p. 64-76, Sum. 2002.

BROWN, J. S.; DUGUID, P. Organizational learning and communities-ofpractice: towards an unified view of working learning and innovation. Organizational Science, v. 2, n. 1, p. 40-57, 1991. 
CHOO, C. W. A organização do conhecimento: como as organizações usam a informação para criar significado, construir conhecimento e tomar decisões. São Paulo: Senac, 2003.

COHEN, D. Towards a knowledge context: report on the first annual U.C. Berkeley Forum on Knowledge and the firm. California Management Review, Berkeley, v. 40, n. 3, p. 22-39, 1998.

DAVENPORT, T. H. Ecologia da informação: por que só a tecnologia não basta para o sucesso na era da informação. São Paulo: Futura, 2000.

DAVENPORT, T. H.; PRUSAK, L. Conhecimento empresarial. 6.ed. Rio de Janeiro: Campus, 1998. 237p.

DAVENPORT, E.; HALL, H. Organizational knowledge and communities of practice. Annual Review of Information, Science and Technology - ARIST, Medford, v. 36, p. 171-227, August 2002.

DIXON, N. Common knowledge: how companies thrive by sharing what they know. Harvard: Harvard Business School Press, 2000.

DOUGHERTY, D. Interpretative barriers to successful product innovation in large firms. Organization Science, v. 3, n. 2, p. 179-202, May 1992.

DYER, J. H.; NOBEOKA, K. Creating and managing a high performance knowledge sharing network: the Toyota case. Strategic Management Journal, v. 21, p. 345-367, 2000.

EMPSON, L. Introduction: knowledge management in professional service firms. Human Relations, New Delhi, v. 54, n. 7, p.811-817, 2001.

ERDELEZ, S. Information encountering: a conceptual framework for accidental information discovery. In: VAKKARI, P; SAVOLAINEN, R.; DERVIN, B. (Eds.). Information seeking in context. London: Taylor Graham, 1997. p.412-421 apud TALJA, S. Information sharing in academic communities: types and levels of collaboration in information seeking and use. New Review of Information Behavior Research, v. 3, p. 143-159, 2002.

IPE, M. Knowledge sharing in organizations: a conceptual framework. Human Resource Development Review, v. 2, n. 4, p. 337-359, Dec. 2003.

JUDGE, W. Q.; FRYXELL, G. E.; DOOLEY, R. S. The new task of R\&D management: creating goal-directed communities for innovation. In.: LESSER, Eric L.; FONTAINE, M. A.; SLUSHER, J. A. (Orgs.). Knowledge and communities. Boston: Elsevier, 2000. cap.3, p. 37-52.

LIN, H. Effects of extrinsic and intrinsic motivation on emplouee knowledge sharing intentions. Journal of Information Science, v. 33, n. 2, p. 135-149, 2007.

NONAKA, I.; TAKEUCHI, H. Criação do conhecimento na empresa. 4.ed. Rio de janeiro: Campus, 1997.

NOWAK, M. A.; SIGMUND, K. Enhanced: shrewd investments. Science, v. 288, n. 5467, p. 819-820, 2000. 
O"DELL, C.; GRAYSON, C. J. If only we knew what we know: identification and transfer of internal best practices. California Management Review, v. 40, p. 3, p. 154- 174, Spring 1998.

POLANYI, M. The tacit dimension. Gloucester, Mass: Peter Smith, 1983.

PONJUÁN DANTE, G. Gestión de información: dimensiones e implementación para el êxito organizacinal. Rosário: Nuevo Parhadigma, 2004.

RULKE, D. L.; ZAHEER, S. Shared and unshared transactive knowledge in complex organizations: an exploratory study. In: SHAPIRA, Z.; LANT, T. (Ed.). Organizational cognition: computation and interpretation. Mahwah, NJ: Lawrence Erlbaum, 2000.

SELAMAT, M. H.; CHOUDRIE, J. The diffusion of tacit knowledge and its implications on information systems: the role of meta-abilities. Journal of Knowledge Management, v. 8, n. 2, p. 128-139, 2004.

STENMARK, D. Leveraging tacit organizational knowledge. Journal of Management Information Systems, v. 17, n. 3, p. 9-24, 2001.

TALJA, S. Information sharing in academic communities: types and levels of collaboration in information seeking and use. New Review of Information Behavior Research, v. 3, p. 143-159, 2002.

TOMAÉL, M. I. et al. Redes sociais em alimentos funcionais no Paraná: relato pesquisa. Encontros Bibli: Revista Eletrônica de Biblioteconomia e Ciência da Informação, Florianópolis, v. 12, n. 24, p. 111-138, 2007. 